\title{
Menstrual Hygiene Practices Among Adolescent Girls in Junior High Schools in Selected Communities of Ashanti Region, Ghana
}

\author{
Alberta David Nsemo ${ }^{1}$, Idang Neji Ojong ${ }^{2}$, Ramatu Agambire ${ }^{1}$, Regina Adu ${ }^{1} \&$ Mercy Dankwah $^{1}$ \\ ${ }^{1}$ Garden City University College, Kenyase, Kumasi, Ghana \\ ${ }^{2}$ University of Calabar, Calabar, Cross River State, Nigeria \\ Correspondence: Alberta David Nsemo, (RN, RM, BNSc., PGDE, MSc., Ph.D, Ph.D), Garden City University \\ College, Kenyase, Kumasi, Ghana. E-mail: albertansemo@yahoo.com
}

Received: April 12, 2020 Accepted: May 17, 2020 Online Published: May 29, 2020

doi:10.5539/gjhs.v12n8p38 URL: https://doi.org/10.5539/gjhs.v12n8p38

\begin{abstract}
Introduction: Menstruation is a phenomenon unique to the females and menstrual hygiene is still a problem for adolescent girls especially in low and middle income countries particularly when attending school. This issue is insufficiently acknowledged and has not received adequate attention in the reproductive health sectors in developing countries including Ghana and its relationship with the achievement of Sustainable Development Goals (SDGs).
\end{abstract}

Objectives: This study examined the knowledge and practices of menstrual hygiene among adolescent girls, the cultural beliefs that influence menstrual hygiene practices, and the problems adolescent girls face in practicing menstrual hygiene.

Methodology: A quantitative research method using descriptive cross-sectional survey design was employed in the study. Using a multi-staged sampling technique, a sample size of 151 adolescents in Juniors High schools who had reached menarche was selected from four (4) schools located in Asamang, Sekyere south District of Ashanti region of Ghana. Data was collected through a researchers' constructed and validated questionnaire titled "Adolescents knowledge and practice of menstrual hygiene questionnaire (AKPMHQ)". Data was analysed using simple frequencies and percentages.

Results: The study revealed that 68(45\%) of the girls were in the Junior High School three (JHS3) and 88(58.5\%) of them ranged between $14-15$ years. Most of them (74.2\%) had pre-menarche education given by their family members. Most of the parents $94(62.3 \%)$ had secondary education. Majority of the girls practiced good menstrual hygiene. Their culture does not exert much influence on their knowledge and practices of menstrual hygiene. However, there were some myths which are not scientifically based. Most of the girls experience some challenges during menstruation such as lower abdominal pain $77(51.0 \%)$ and unavailability of facility in school to change during menstruation 61(40.4\%).

Conclusion: The adolescent girls are knowledgeable about menstrual hygiene and also have good menstrual hygiene practices. However, there exist few cultural practices in the community that may have negative effect on their knowledge and practice of menstrual hygiene in the midst of some physical and social challenges experienced by the adolescents during menstruation.

Keywords: Adolescent girls, menstrual hygiene, knowledge, practices, culture

\section{Introduction}

Menstruation is the periodic blood that flows as a discharge from the uterus through the vagina. It occurs as a result of cycle of events in the ovaries which produces changes not only in the uterus but in the female body as a whole. (Fraser \& Copper, 2009). It begins between the ages of 11-15 years with a mean of 13years and continuous throughout the child bearing years and ends around age 55years (Aluko et al., 2014). The average length of the cycle is 28 days although there are considerable variations among women and monthly cycles. The blood flow last for an average period of 4-5 days and the amount lost is between 50-150ml but the duration and amount also vary from each woman (Fraser \& Copper, 2009). Girls in many low- and middle-income countries (LMIC) enter puberty with knowledge gaps and misconceptions about menstruation, unprepared to cope with it and unsure of when and where to seek help. This is because the adults around them, including parents and teachers, are 
themselves ill-informed and uncomfortable discussing sexuality, reproduction and menstruation (Lee et al., 2006). The manner in which a girl learns about menstruation and its associated changes may have an impact on her response to the event of menarche. As stated by Rao, Joshi and Kanade, (2009) menstruation is a natural process but it is linked with several misconceptions and practices, which sometimes result into adverse health outcomes. Similarly a study conducted in south eastern Nigeria revealed that up to $44.8 \%$ of the adolescent girls had no pre-menarcheal training, which resulted in inappropriate menstrual experiences and poorer menstrual hygiene practice (Aluko et al., 2014).

Effective menstrual hygiene management is vital to the health, wellbeing, dignity, empowerment, mobility and productivity of women and girls. Poor menstrual hygiene may cause stigma and ill health, and can lead to school absenteeism and increased school dropout rates (Poureslami \& Osati-Ashtiani, 2002). Hygiene related practices of women during menstruation are of considerable importance, especially in terms of increased vulnerability to reproductive tract infections (RTIs), hence women having better knowledge regarding menstrual hygiene and safe practices are less vulnerable to RTI and its consequences (Phani et al., 2019). Good menstrual hygiene management involves women or adolescent females using clean blood-absorbing materials which can be changed often in a secure place in privacy, after which soap and water are available to wash hand and body as well as having access to secured used sanitary material disposal facility (UNESCO, 2014).

In Ghana a study found that, menstrual hygiene practices among basic school level in urban settings were good with socio-economic factors contributing to the use of good disposable menstrual product (Blessing, 2016). In the contrary, a study by Asimah, Diabene and Wellington (2017) revealed that at school girls were limited in managing their menstrual periods than at home even though there were still societal restrictions on menstrual hygiene methods at home. This limitation was due to the fact that they stayed in the same room with many other children and had anxieties about whether or not they would have menstrual accidents (Asimah et al., 2017). Menstruation has always been surrounded by different perceptions throughout the world. Differences still exist between countries, cultures, religions and ethnic groups. In many low income countries, during menstruation girls are still perceived to be impure, causing the girl under menstruation to nurse feelings of shame and un-cleanliness. Even today menstruation is a secret of mother and daughter, as it is not discussed openly in many families (Ali \& Rizvi, 2010). Studies conducted across the world have shown inadequate knowledge and practice of menstruation hygiene among adolescent and pre-tertiary students (Water Aid, 2009). In lieu of this, knowledge, practices and information regarding optimal menstrual hygiene still needs to be explored especially in rural settings. The understanding of these will help to put proper menstrual management measures in place. With this background, the study specifically sought to address the following questions;

1) Are adolescent girls in Asamang knowledgeable about menstrual hygiene practices?

2) How do the adolescent girls practice menstrual hygiene?

3) What are the cultural beliefs that influence menstrual hygiene practices among adolescent girls?

4) What problems do adolescent girls face when practicing menstrual hygiene?

\section{Operational Definition of Terms}

Adolescent girl: A girl between the ages of 10-18 years

Junior High School (JHS): The school level between primary and secondary school

Menarche: The first experience of menstruation by a girl

Menstrual hygiene practices: Whatever the adolescent girl does to maintain proper hygiene and cleanliness during menses

Premenstrual Training/Education: Coaching about menstruation before it starts.

\section{Materials and Methods}

The study utilized a cross-sectional descriptive design. The study was conducted in Asamang, a town in Sekyere South District of Ashanti region. The town has four (4) electoral areas: Aburaso, Ahenbronum, Siawuo and Konya/Brehoma and a total population of about 6,983. It shares boundaries with Agona on the north, on the east with Mampong Municipal Assembly, south with Sekyere East and west with Kona. There are four (4) Basic and Junior High Schools, one senior high School and one University College, as well as a hospital operated by the Seventh Day Adventist Church. The people of Asamang are mostly farmers with few traders and government workers. Majority are also Christians whilst the others are Muslims and traditionalist.

The study population is adolescent girls in junior high schools in Asamang between the ages of 12 and 19 years. 
This group was chosen because they might have experienced menarche and therefore will be able to share experiences associated with menstruation. Those students who had attained menarche at the beginning of the study were included and those who were not willing to take part in the study as well as those who had not reached menarche were excluded from the study. The total number of students was 276 with the breakdown as shown in Table 1.

Table 1. Distribution of students based on the four (4) schools selected (N=276)

\begin{tabular}{llll}
\hline S/N & SCHOOL & LEVEL & NUMBER OF STUDENTS \\
\hline 1 & Asamang D/A & Junior Secondary school (JSS) & 32 \\
2 & Seventh Day Adventist JSS & JSS & 106 \\
3 & Amoakohene JSS & JSS & 100 \\
4 & Presbyterian JSS & JSS & 38 \\
\hline
\end{tabular}

Source: Data gotten from accessible population in each school.

The sample size of 151 girls who had reached menarche were selected using the following statistical formula: $\mathrm{n}=\mathrm{Z}^{2}$ $\mathrm{p}(1-\mathrm{p}) / \mathrm{w}^{2}$ where:

$\mathrm{N}=$ Sample size

$\mathrm{Z}=$ Confidence interval

$\mathrm{p}=$ Proportion of adolescent girls

$\mathrm{w}=$ Margin of error

$\mathrm{n}=(1.96)^{2 *}(0.1 * 0.9) /(0.05)^{2}$

$\mathrm{n}=3.842 * 0.09 / 0.0025$

$\mathrm{n}=0.34578 / 0.0025$

$\mathrm{n}=138$

Attrition rate of $10 \%=13$

$\mathrm{N}=151$

The town has four junior high schools. Multi-staged sampling technique was used to select participants for the study. All the four (4) schools were purposely selected, and each school was further stratified based on their sections. For selection of representative numbers of students, the ratio of students in the respective school and class were considered. The sample size was allocated for the schools using population proportion to the sample for each selected school. Finally, proportional number of participants (students) was selected by simple random sampling technique from each class. The sampling frame was obtained from the student registration books of the respective schools. Thus the sample size for the study as drawn from each school are represented below in Table 2.

Table 2. Showing the distribution of study sample based on the selected schools ( $N=151)$

\begin{tabular}{cllllc}
\hline Class & SDA & Amoakohene & Presby & D/A & Total \\
\hline JSS 1 & 13 & 10 & 5 & 4 & 32 \\
JSS2 & 20 & 16 & 8 & 7 & 51 \\
JSS3 & 20 & 24 & 6 & 18 & 68 \\
Total & 53 & 50 & 19 & 29 & 151 \\
\hline
\end{tabular}

Source: field survey.

Data was collected through a researchers' constructed and validated questionnaire titled "Adolescents knowledge and practice of menstrual hygiene questionnaire (AKPMHQ)". The instrument was made up of four (4) sections viz; Section A: covered Socio- Demographic Data of the respondents, Section B: was on Knowledge about menstrual hygiene practice, Section C: examined Practice of menstrual hygiene, Section D: was on Cultural beliefs 
infringing on menstrual hygiene practices, while Section E: was on challenges of practice of menstrual hygiene. Face validation was done by experts in test and measurements. Its reliability was assured through reliability test using Chrombach's Alpha method which yielded a high reliability coefficient of $81.0 \%$.

Before the sampling was done, explanation and the purpose of the study were given to the students including the option to participate or withdraw. After this, those who opted to participate signed the consent form and they were given numbers after which the numbers were written on pieces of paper, reshuffled and picked at random. Any girl whose number was picked was selected until the number for that school was selected. The selection was done with replacement giving every student an opportunity of being selected. Before the study, a formal written permission was obtained from District Education Directorate, same presented to the head teachers of the schools. The study instruments were self-administered. On the spot data collection was done by the researchers. Regular verification and validation of data were done with all inconsistencies being checked and resolved. Data collected was analysed using SPSS, version 21.0, and findings presented in frequencies, percentages and bar charts. Institutional Ethical committee approval was obtained before conducting the study. In addition, participation was voluntary, and respondents were assured of confidentiality of the information provided, hence personal identifiers were removed from the data summary.

\section{Results}

Table 3. Distribution of Study population according to socio-demographic factors

\begin{tabular}{lll}
\hline Variable & Number (151) & Percentage \\
\hline Age & 39 & 25.8 \\
$12-13$ & 88 & 58.3 \\
$14-15$ & 20 & 13.2 \\
$16-17$ & 4 & 2.6 \\
$18-19$ & & \\
\hline Religion & 133 & 88.1 \\
Christianity & 15 & 9.9 \\
Moslem & 3 & 2.0 \\
Traditionalist & 0 & 0 \\
Others & & \\
\hline Class of Adolescent Girl & 32 & 21.2 \\
Form one & 51 & 33.8 \\
Form Two & 68 & 45.0 \\
Form Three & &
\end{tabular}

Field survey, 2020.

Table 4. Education and occupation Distribution of Respondents' Parents/Guardians

\begin{tabular}{lcc}
\hline Variable & Number (151) & Percentage (100) \\
\hline Education of Parents & 42 & 27.8 \\
Primary & 94 & 62.3 \\
Secondary & 11 & 7.3 \\
Tertiary & 4 & 2.6 \\
Others (No education) & & \\
\hline
\end{tabular}




\section{Occupation of Parents}

$\begin{array}{lcc}\text { Farming } & 82 & 54.3 \\ \text { Trading } & 60 & 39.7 \\ \text { Teaching } & 6 & 4.0 \\ \text { Others } & 3 & 2.0\end{array}$

Field survey, 2020.

Table 4 shows that majority $88(58.3 \%)$ of the participants aged between 14 and 15 years and only $4(2.6 \%)$ were between age 18-19. Out of this, 133(88.1) were Christians and few 3(2\%) were traditional worshipers. Sixty eight $(45 \%)$ of the respondents are in JHS3 and those in JSS 1 were 32 representing $21.2 \%$. The educational background of most of their parents shows that $94(62.3 \%)$ attained secondary level education and $4(2.6 \%)$ had no education. The occupation of majority $82(54.3 \%)$ of their parents was farming and $6(4 \%)$ were teachers.

Table 5. Participants' Knowledge about Menstrual Hygiene Practice (N=151)

\begin{tabular}{lll}
\hline Variable & NUMBER & PERCENTAGE \\
\hline Knowledge about menstrual hygiene before menarche & & 16.6 \\
No & 25 & 83.4 \\
Yes & 126 & 55.6 \\
\hline Source of Information about menstrual hygiene & 84 & 6.0 \\
Family member & 9 & 37.1 \\
Friend & 56 & 0.7 \\
Teacher & 1 & 0.7 \\
Social media & 1 & \\
Friend and Teacher & & \\
\hline
\end{tabular}

\begin{tabular}{|c|c|c|}
\hline Knowledge about where Menstrual blood come from & & \\
\hline Uterus & 19 & 12.6 \\
\hline Vagina & 109 & 72.2 \\
\hline Abdomen & 6 & 4.0 \\
\hline No idea & 17 & 11.3 \\
\hline \multicolumn{3}{|l|}{ Knowledge of how often a girl should menstruate in a month } \\
\hline Once every month & 127 & 84.1 \\
\hline Once every other month & 5 & 3.3 \\
\hline Twice every month & 16 & 10.6 \\
\hline Other & 3 & 3.0 \\
\hline \multicolumn{3}{|l|}{ Knowledge about menstrual hygiene practice } \\
\hline 1. Bath twice a day & 112 & 74.2 \\
\hline 2. Insert your finger in the vagina to clear dead blood & 14 & 9.3 \\
\hline 3. Wash hand before and after changing pad & 20 & 13.3 \\
\hline 4. Use chemical to bath & 5 & 3.3 \\
\hline \multicolumn{3}{|l|}{ Were you given any premenstrual training before menarche } \\
\hline Yes & 112 & 74.2 \\
\hline No & 39 & 25.8 \\
\hline
\end{tabular}




\section{Duration of menstrual flow}

Less than 3 days

8

4-5 days

More than 7 days

Field survey, 2020.

Table 5 shows that respondents had good knowledge of menstrual hygiene practices. Out of 151 respondents, $126(83.4 \%)$ indicated that they had knowledge about menstrual hygiene before menarche. For 84 (55.6\%), the information about menstrual hygiene was given by a family member, whilst $1(0.7 \%)$ had the information from the social media, friends and teachers. Majority of the respondents $109(72.2 \%)$ knew that the menstrual blood comes from the vagina, while $17(11.3 \%$ ) had no knowledge about where it comes from. Most of the respondents, 127 $(84.1 \%)$ said menstruation comes every month while $3(3.0 \%)$ said it comes twice a month. Most of the respondents $112(74.2 \%)$ said that they were taught to bath twice during menstruation. Most of the respondents $112(74.2 \%)$ indicated they were given pre-menstrual training before menarche, and 97(64.2\%) knew that the menstrual blood should last between four to five days.

Table 6 shows that respondents had good menstrual hygiene practices. Out of the 151 respondents, 96(63.6\%) indicated that when their periods start at school, they go home immediately while a few 5(3.3\%) wait until school closes before going home. Majority of them 139 (92\%) said they use sanitary pad for the menstrual flow, whilst $1(0.7 \%)$ mentioned the use of tissue paper and menstrual cup respectively. Most of them 103(68.2\%) dispose their used menstrual material into the toilet and 3(2.0\%) reuse the material. They all said they wash the washable menstrual materials with soap and water and dry $151(100 \%)$. Ninety seven $(64.2 \%)$ of them use tap water during menstruation, and $115(76.2 \%)$ of the respondents change their menstrual material twice a day.

Table 6. Showing Respondents' menstrual hygiene practices $(\mathrm{N}=151)$

\begin{tabular}{|c|c|c|}
\hline & NUMBER & PERCENTAGE \\
\hline \multicolumn{3}{|c|}{ What do you do when your period starts in school } \\
\hline I tell my teacher for help & 48 & 31.8 \\
\hline I tell a friend for help & 2 & 1.3 \\
\hline I go home immediately & 96 & 63.6 \\
\hline I wait until school closes & 5 & 3.3 \\
\hline \multicolumn{3}{|l|}{ Material used when menstruating } \\
\hline Sanitary pad & 139 & 92.0 \\
\hline Menstrual cup & 1 & 0.7 \\
\hline Old cloth & 10 & 6.6 \\
\hline Tissue paper & 1 & 0.7 \\
\hline \multicolumn{3}{|c|}{ How do you take care of the menstrual material after use } \\
\hline Disposed into a dust bin & 42 & 27.8 \\
\hline Disposed into the bush & 3 & 2.0 \\
\hline Disposed into toilet & 103 & 68.2 \\
\hline Washed and reuse & 3 & 2.0 \\
\hline \multicolumn{3}{|l|}{ Care of reusable material } \\
\hline Soak, wash and dry & 0 & 0 \\
\hline Wash with hot water and dry & 0 & 0 \\
\hline Wash with soap and water and dry & 151 & 100 \\
\hline Others & 0 & 0 \\
\hline
\end{tabular}


Does the kind of water used during menstruation affect menstrual hygiene

$\begin{array}{llr}\text { Yes } & 53 & 35.1 \\ \text { No } & 98 & 64.9\end{array}$

\begin{tabular}{lll}
\hline The common household water used during menstruation & & 67.2 \\
Tap water & 51 & 33.8 \\
Bore whole & 3 & 2.0 \\
River and Stream & 0 & 0 \\
Others & 15 & 76.9 \\
\hline How often do you change your menstrual material during menstruating & 115 & 12.6 \\
Once a day & 19 & 1.3 \\
Twice a day & 2 & 2.3 \\
Thrice a day & & \\
More than thrice & & \\
\hline
\end{tabular}

Field survey, 2020.

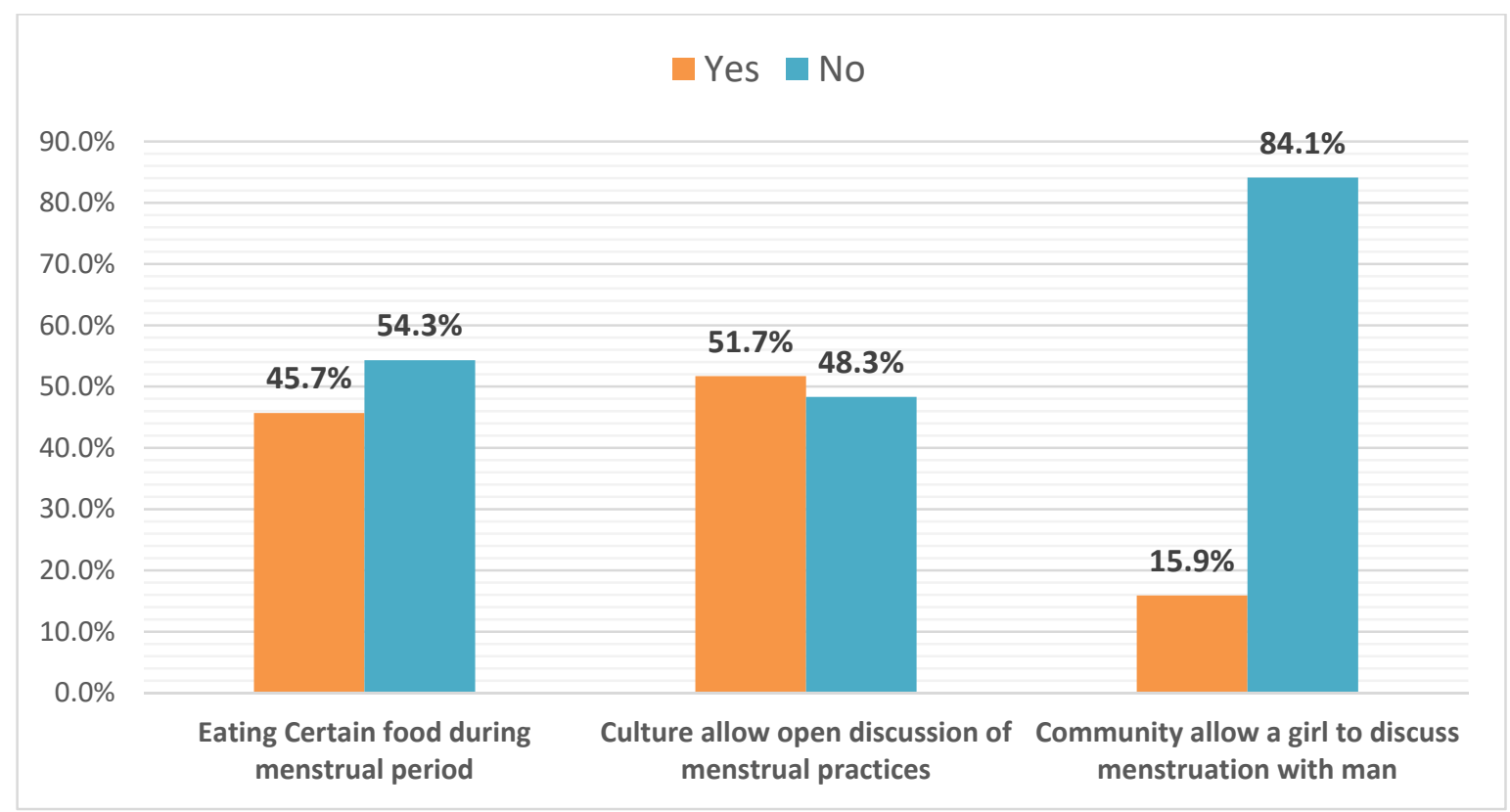

Figure 1. Distribution of adolescent girls regarding restrictions practiced during menstruation

Figure 1 shows that most $127(84.1 \%)$ of the respondents indicated that they are not allowed to discuss menstruation with men, and $82(54.3 \%)$ said they are not restricted from eating certain food. Majority 78 (51.7\%) said their culture allows open discussion of menstrual practices. 
Table 7. Community belief and practices in relation to menstruation

\begin{tabular}{|c|c|c|}
\hline Variable & Number & Percentage \\
\hline \multicolumn{3}{|l|}{ How do your Community members see menstrual blood } \\
\hline Normal physiological process & 55 & 36.4 \\
\hline Release of bad blood & 43 & 28.5 \\
\hline Cleansing of the womb & 14 & 9.3 \\
\hline No idea & 39 & 25.8 \\
\hline \multicolumn{3}{|l|}{ What belief or myths does your community have in relation to menstruation } \\
\hline You will become sick when your menstrual pad is seen by another. & 52 & 34.4 \\
\hline Some people bleed from their palm & 43 & 28.5 \\
\hline Eating certain foods can cause abdominal crams & 48 & 31.8 \\
\hline Others (don’t know) & 8 & 5.3 \\
\hline \multicolumn{3}{|l|}{ What is your community belief about burning of sanitary pad } \\
\hline The girl will be unable to give birth & 52 & 34.4 \\
\hline The girl will not menstruate again & 15 & 9.9 \\
\hline It accepted to be burnt & 51 & 33.8 \\
\hline No idea & 33 & 21.9 \\
\hline \multicolumn{3}{|l|}{ What restriction does your culture impose on you during menstruation } \\
\hline Not allowed to cook & 56 & 37.1 \\
\hline Not allowed to go to place of worship & 50 & 33.1 \\
\hline Not allowed to go to river side & 40 & 26.5 \\
\hline Others (palace) & 5 & 3.3 \\
\hline \multicolumn{3}{|l|}{ What is your belief about drying of reusable sanitary material in the opened } \\
\hline It is a taboo for others to see such material & 52 & 34.4 \\
\hline Is shameful for others to see & 32 & 21.2 \\
\hline It is good to dry them outside & 47 & 31.1 \\
\hline No idea & 20 & 13.3 \\
\hline
\end{tabular}

Field survey, 2020.

From Table 7, according to $55(36.4 \%)$ of the respondents, the community see the menstrual blood as a normal physiological process whilst $14(9.3 \%)$ see it to be the cleansing of the womb. Majority 52 (34.4\%) indicated that it is a belief in the community that if another person see your menstrual pad you will become sick but few of them 8 $(5.3 \%)$ had no idea about such belief. Majority, $52(34.4 \%)$ of the respondents indicated that it is their belief that if the menstrual pad is bunt, the girl will not be able to give birth, while $15(9.9 \%)$ indicated that the person will not menstruate again. Majority $56(37.1 \%)$ responded that a menstruating woman is restricted from cooking in the community, $50(33.1 \%)$ indicated that they are not allowed into the places of worship, 40 (26.5\%) indicated that they are not allowed to go to the river side, while 5(3.3\%) indicated that they are restricted from going to the palace. Majority of the respondents, $52(34.4 \%)$ responded that it is a taboo in the community to dry reusable menstrual material outside for others to see. However 20 (13.3\%) of the respondents had no idea about such belief. 
Table 8. Challenges When Practicing Menstrual Hygiene

\begin{tabular}{|c|c|c|}
\hline Variable & Number & Percentage \\
\hline \multicolumn{3}{|c|}{ What are some of the physical challenges you face during menstruation } \\
\hline Headache & 42 & 27.8 \\
\hline Depressed & 32 & 21.2 \\
\hline Lower abdominal pain & 77 & 51.0 \\
\hline \multicolumn{3}{|c|}{ How do you manage these physical challenges during menstruation } \\
\hline Take over the counter drug & 51 & 33.8 \\
\hline Take traditional medicine & 27 & 17.9 \\
\hline Go to the hospital & 66 & 43.7 \\
\hline Others (do nothing) & 7 & 4.6 \\
\hline \multicolumn{3}{|c|}{ What problems do you face in getting proper menstrual material to use } \\
\hline Products not available in my community & 15 & 9.9 \\
\hline I do not have money to buy the material & 45 & 29.8 \\
\hline The products are expensive & 24 & 15.9 \\
\hline I do not have any problem to get the material & 67 & 44.4 \\
\hline \multicolumn{3}{|c|}{ How do your mates react when they see you menstruating } \\
\hline They tease me & 14 & 9.3 \\
\hline I am ignored & 12 & 7.9 \\
\hline They show support & 107 & 70.9 \\
\hline They are in different & 18 & 11.9 \\
\hline \multicolumn{3}{|c|}{ Does the fear of staining yourself interfere with your studies } \\
\hline All the time & 23 & 15.2 \\
\hline Sometimes & 64 & 42.4 \\
\hline Most of the time & 21 & 13.9 \\
\hline Not at all & 43 & 28.5 \\
\hline \multicolumn{3}{|c|}{ Do you have privacy to change menstrual materials in school } \\
\hline YES & 92 & 61.0 \\
\hline NO & 59 & 39.0 \\
\hline \multicolumn{3}{|c|}{ How will you rate the facilities available for you to change yourself when menstruating? } \\
\hline Adequate & 50 & 33.1 \\
\hline Not adequate & 26 & 17.2 \\
\hline Not available at all & 61 & 40.4 \\
\hline Neutral & 14 & 9.3 \\
\hline
\end{tabular}

Field survey, 2020.

As shown in table eight, challenges experienced by respondents during menstruation were; lack of money to purchase menstrual materials $45(29.8 \%)$, fear of staining themselves during menstruating sometimes interferes with their studies $64(42.4 \%$ ), and unavailability of facilities in school to change during menstruation $61(40.4 \%)$, leading to lack of privacy to change during menstruation in school as expressed by 59(39\%) of the respondents. These challenges occur in addition to the physical challenges they experience, such as lower abdominal pains during menstruation 77(51.0\%), headache $42(27.8 \%)$. However, 107 (70.9\%) respondents indicated enjoying some form of support from their mates during this period. 


\section{Discussion of Findings}

Majority of the adolescent girls in the junior high schools in Asamang had good knowledge of menstrual hygiene practices. Most of them gained this knowledge before menarche, taught them by their family members. This is consistent with the findings of the study by Parajuli, Paradel and Shresta (2017), which showed that majority of the girls had knowledge of menstruation, and in more than half of the respondents, their mothers taught them about menstruation. This may be attributed to the educational level of the parents being secondary school level. Similar results were obtained by Lawan et al. (2010); George (2012). This observation is likely because mothers are often the closest informant and "teacher" of the growing adolescent girls owing to their similarities in reproductive physiology (Ali \& Rizvi, 2010). However, some studies have revealed that information on menstruation given by the mother is often incomplete and incorrect, usually being based on cultural myths, and therefore probably perpetuating negative and distorted perceptions and practices of menstruation (Lee et al., 2006). Very few of them had the information from the social media and teachers. This may indicate that the girls are not having access to phones and at the same time their teachers are also not giving them information about menstruation. Most of them mentioned that they were between ages 13-14 years when they were given information about menstrual hygiene. This is in consonant with what was found by George (2012) that adolescent girls above age 12 had $61.8 \%$ rating in knowledge on menstrual hygiene than those younger than 12 years who had had poor knowledge about menstrual hygiene practices, even though they had attained menarche, which contradict what was found by Lawan et al. (2010) that most respondents $85.4 \%$ knew about menstruation before menarche. In response to where the menstrual blood comes from, Majority of the respondents knew that the menstrual blood comes from the vagina, which disagrees with the findings of study by Ahuja \& Tiwari (2009), which revealed that about three-quarters of girls were ignorant about the physiology of menstruation. Majority of the respondents knew that menstruation comes every month. This indicates that the family members are giving the girls right information about the physiology of menstruation. Most of the respondents were taught to bath twice during menstruation. Chauhan, et al (2019) found similar results that about $71.7 \%$ of the adolescents they studied knew that unhygienic conditions put them at risk of genital infections. However in the same study, they found that all the respondents took a daily bath. Most of the respondents indicated they were given pre-menstrual training before menarche which is consistent with what was found by George (2012) that most of the adolescent school girls (92.2\%) had pre-menarcheal counselling. Also most of them know that the menstrual blood should last between four to five days. This knowledge may have resulted from the pre-menarcheal training they had.

Furthermore, the findings showed that the adolescent school girls exhibited good menstrual hygiene practices. Majority (63.6\%) of the respondents indicated that when their menses start at school, they go home immediately. Trinres, et al. (2015) also found similar report that majority of girls would go home immediately if their period started while at school. This may be either due to lack of facility in the school to accord them the privacy to change, or their unpreparedness for the menses or because they live closer to the school and the few who wait until school closes before going home may have prepared for it. Additionally Majority of them used sanitary pad for the menstrual flow. This is contradictory to what was found by Dasgupta and Sarkar (2007) in which a total of $11.25 \%$ of the girls used sanitary pads. Similarly, the study by Thakre, et al. ((2011), 45.74\% of the girls used old cloth during menses, unlike what was found in our study where only $6.6 \%$ used old cloths. The pre-menarcheal training given to the girls may have contributed to this practice. On the disposing of menstrual materials, most of the respondents disposed their used menstrual materials into the toilet and those who used reusable material washed them with water and soap and dried. Related to this, Thakre, et al., (2011) found in their study that $41.86 \%$ of the girls used cloth material but did not clean it properly. Unlike our study in which only $2 \%$ use re-useable material even though the setting is rural. The pre-menarcheal training may as well have been a contributory factor. There was lack of knowledge on the potential for contaminated water to cause infection since (64.9\%) of them indicated that the type of water used during menstruation does not have any effect on menstrual hygiene. This notwithstanding, majority of them use tap water during menstruation. Most of the respondents indicated changing their menstrual material twice a day which agrees with what was found in the study by Ibaishawa and Achakpa (2016), which observed that $61.3 \%$ changed the menstrual pad/material 2-3 times a day. This indicates averagely good menstrual hygiene management practice.

Regarding the cultural beliefs infringing on menstrual hygiene practices, most $(84.1 \%)$ of the respondents indicated that they are not allowed to discuss menstruation with men. This may account for why most of the girls run home when their menses start in the school especially if their teachers are males. About an average number (54.3\%) of respondents said they are not restricted from eating certain food, contradicting the study by Trinvres, et al (2015); Kumar and Srivastava (2011), in which strict dietary restrictions such as eating of sour food are imposed on women and girls during menstruation in some parts of India. The belief is that eating such foods will disrupt the 
menstrual flow. Most of the respondents indicated their culture allows open discussion of menstrual practices. This is not consistent with the study by Kaur et al. (2018) in which it was found that men do not support women regarding menstrual hygiene and have never discussed menstrual issues with their wives and daughters. According to $36 \%$ of the respondents, the community members see the menstrual blood to be a normal physiological process. The same result was found in the study by Parajuli, Paradel and Shresta (2017), in which majority (83.3\%) of the girls had knowledge that menstruation is a physiological process, contrary to Wateraid (2012) in Surinam, who found in their study that menstrual blood is perceived to be dangerous. Most of the respondents indicated the presence of some myths in the community that one will become sick if the menstrual pad is seen by another person. The study in Surinam found similar results (Wateraid, 2012), and added that a bad person can use black magic to harm a menstruating woman or girl when seen. However, majority had no idea about any belief concerning burning of sanitary pad, but a few indicated that there is a belief that if the sanitary pad is burnt, the girl will not menstruate again. This supports what was found among the girls from the slums, in a study by Kumar and Srivastava (2011). This findings show that their knowledge about the physiology of menstruation is not adequate and therefore the need to be educated properly. Fifty six $(37 \%)$ respondents said their culture restrict them from cooking when menstruating. Kumar and Srivastava (2011) found similar restriction in their study. Five (3.3\%) said menstruating women are not supposed to go to the palace. However none of the reviewed literature mentioned this restriction. Millington and Bolton (2015) similarly found that reusable menstrual products are not washed and dried properly by the girls because there is the taboo around menstruation that such items cannot be dried outside which makes the girls hide them under their bed or on thatched roof to dry. In this current study majority of them said it a taboo in the community to dry reusable material in the open for others to see supporting what had been found earlier. This practice will likely make the materials contaminated and increases the risk of the girls getting infections.

Majority of the respondents indicated their experience of physical discomfort during menstruation, such as 77 (51.0\%) lower abdominal pains. Dogbetor (2015) cited that Montgomery (2012) found that girls missed up to 5 days in a month from school due to physical discomfort such as cramps during menstruation. In managing this, Montgomery's study revealed that the girls took pain killers to relieve the pain, while in our study, majority of the girls go to the hospital to manage the physical challenges they have during menstruation. The presence of a hospital in the community and the menstrual practice education by family members may have contributed to this behaviour. Most of them 67 (44.4\%) do not have any problem getting menstrual material to use. However according to Pandey (2014), for some women particularly those living in poverty, it may still be a struggle to have access to products even in countries where the products are available. This hold true for $(29.8 \%)$ of them who indicated they do not have money to buy the menstrual material. Poor accessibility to feminine hygiene products can lead to girls and young women missing school and even contracting infection. In Montgomery's (2012) study, some girls indicated that they did not bring menstrual material to the school because they feared that other students may see them in their bags and make fun of them. However in our study, majority of the respondents indicated that their mates show support when they see them menstruating. This shows that the mates show maturity in such matters. Majority of them also indicated that the fear of staining themselves when menstruating sometimes interferes with their studies. This is similar to findings of Pandey (2014), in which the girls indicated that in the classroom they are particularly cautious about their movement. A lot of care was taken when standing, sitting and walking all because of the fear of staining their uniform accidentally. This shows the need for the girls to be educated on the use of proper menstrual material during menstruation. Lack of place to change used menstrual materials at school was indicated as a huge challenge by $61(40.4 \%)$ of the respondents. It could mean that those who indicated to have privacy have their homes close to the school and therefore can have access to private room to change.

\section{Summary and Conclusion}

Our study found that the adolescent girls in JHS in Asamang district in Kumasi, Ghana, had good knowledge of menstrual hygiene which translated into good menstrual hygiene practices. The cultural beliefs in the community do not impose so much restriction on the girls regarding their menstrual practices, however, there were some myths which are not scientifically based. For the adolescent girls, experience of menstruation was not devoid of challenges, amidst physical challenges. The study therefore concludes that;

- Most of the adolescent school girls under study were between the ages of 13-14 years of age, and had pre-menstrual training by their family members.

- Majority of them lacks knowledge about the source of menstrual blood. However, they know that, menstrual flow should last for 4-5days.

- Most of the girls were unprepared for menstruation and had to rush home any time they have their menses 
in school.

- Most of the girls uses sanitary pads and disposed them into the toilet, and this practice could cause potential sewage blockage. Those who were using reusable materials washed them with soap and water before drying them. Some lack the knowledge that contaminated water can cause infection during menstruation.

- Their culture discourages them from discussing menstruation issue with men. It was also a taboo to dry reusable materials in the open for everyone to see.

- They had no restriction to the type of food they are to eat during the period of menstruation. However, most of them were restricted from cooking.

- They have a myth that, when someone sees the used sanitary pad, the menstruating girl will become sick. Also, when the sanitary pad is burnt the person will not menstruate again.

- Fear of being soiled with menstrual flow was among the challenges experienced by most of the girls, which sometimes disrupt their studies if it occur. Physical challenges included having lower abdominal pains during menstruation. However, their friends act as a major support during menstruation in school.

- Majority of the girls indicated lack of facilities to accord them the privacy to change menstrual materials.

\section{Recommendations}

Based on the findings of the study, the following recommendations were made;

1. Pre-menstrual education should be made a core component of the school curriculum for the JHS level, where normal physiology of menstruation will be taught. This will inculcate into the girls the right knowledge about menstrual hygiene practices to prevent infection and ill health. With such knowledge, most of the cultural beliefs and myths about menstruation will be disregarded.

2. The Ministry of Gender and Social Protection should institute distribution of menstrual pad to the adolescent girls in vulnerable areas so that those who cannot afford to buy the pad can benefit.

3. Schools could liaise with the District Assembly to assist in the provision or construction of a decent place of convenience for the schools, to accord the girls privacy when changing during menstruation.

4. A specific waste bin could be provided at strategic points in the school for menstrual material disposal, which should subsequently be sent to the regular waste removal. This will prevent menstrual waste disposal into the toilet causing blockage.

5. Parents should educate their teenage girls on the proper application of menstrual material to prevent soiling themselves while in schools.

\section{Implication of the Study}

The onset of menstruation is one of the most important changes occurring among the girls during the adolescent years. Knowledge of menstrual hygiene and hygiene-related practices of adolescent girls during menstruation are of considerable importance, as it has a health impact in terms of increased vulnerability to reproductive tract infections (RTI). This, if occurs may have a long term maternal morbidity effect on the adolescent girl, which by extension could encroach on the achievement of Sustainable Development Goal 3(Good health and wellbeing).

\section{Suggestion for Further Studies}

This study should be replicated as a comparative study in other schools within the rural communities of Ghana using a larger sample size for generalization to be made.

\section{Acknowledgements}

We gratefully acknowledge the active participation of adolescent girls in the Junior High Schools under study, the principal and the teachers for their cooperation in supporting the study.

\section{Competing Interests Statement}

The authors declare that there are no competing or potential conflicts of interest.

\section{References}

Ali, T. S., \& Rizvi, S. N. (2010). Menstrual knowledge and practices of female adolescents in urban Karachi, Pakistan. Journal of Adolescence, 33, 531-541. https://doi.org/10.1016/j.adolescence.2009.05.013

Aluko, O. O., Oluya, O. M., Olaleye, O. A., Olajuyin, A. A., Olabintan, T. F., \& Oloruntoba-Oju, O. I. (2014). 
Knowledge and menstrual hygiene practices among adolescents in senior secondary schools in Ile Ife, south-western Nigeria. Journal of water, sanitation and hygiene for development, 4(2), 248-256. https://doi.org/10.2166/washdev.2014.084

Ahuja, A., \& Tewari, S. (1995). Awareness about pubertal changes among adolescent girls. Journal of Family Welfare, 41(1), 46-50.

Asimah, S. A., Diabene, P. Y., \& Wellington, S. N. L. (2017). Menstrual hygiene management in Ghana: Understanding the socio-cultural, economic, political factors, challenges and opportunities. In Proceedings of the 40th WEDC International Conference, Loughborough, UK (pp. 24-28). Retrieved from https://dspace.lboro.ac.uk/2134/31431 and Hygiene

Chauhan, P., Shaik, R. A., Anusha, D. V. B., \& Sotala, M. (2019). A study to assess knowledge, attitude, and practices related to menstrual cycle and management of menstrual hygiene among school-going adolescent girls in a rural area of South India. International Journal of Medical Science and Public Health, 8(2), 114-119. https://doi.org/10.5455/ijmsph.2019.1131809112018

Dasgupta, A., \& Sarkar, M. (2007). Menstrual hygiene: How hygienic was the adolescent girl? Indian journal of community medicine: official publication of Indian Association of Preventive \& Social Medicine, 33(2), 77-80. https://doi.org/10.4103/0970-0218.40872

Dorgbetor, G. (2015). Mainstreaming MHM in schools through the play-based approach: lessons learned from Ghana. Waterlines, 34(1), 41-50. https://doi.org/10.3362/1756-3488.2015.005

Ibaishwa, R. L., \& Achakpa, P. M. (2016). Menstrual hygiene management amongst marginalized physically challenged women and adolescent girls in 10 states of Nigeria. http://www.wecf.eu/download/2016/december/nigeria_study1mhm-wep

Kaiser, S. (2008). Menstrual Hygiene Management. Retrieved March 25 2019, from: http://www.sswm.info/content/menstrual-hygiene-management

Kumar, A., \& Srivastava, K. (2011). Cultural and social practices regarding menstruation among adolescent girls. Soc Work Public Health, 26, 594-604. https://doi.org/10.1080/19371918.2010.525144

Kumari, S. (2017). Social, cultural and religious practices during menstruation. Journal of Development and Management Studies XISS, Ranchi, 15(3), 7451-7459.

Lawan, U. M., Yusuf, N. W., \& Musa, A. B. (2010). Menstruation and menstrual hygiene among adolescent school girls in Kano, North western Nigeria. African Journal of Reproductive Health, 14(3), 201-207.

Lee, L. K., Chen, P. C., \& Lee, K. K. (2006). Menstruation among adolescent girls in Malaysia a cross sectional school survey. Singapore Med J, 47(10), 869-74.

Matrika, C. J. (2009). The Mythic Origins of the Menstrual Taboo in the Rig Veda. Retrieved April 2019, from http://www.matrika-india.org/Research/MythicOrigins.html .

Millington, K. A., \& Bolton, L. (2015). Improving access to menstrual hygiene products (GSDRC Helpdesk Research Report 1280). Birmingham, UK: GSDRC, University of Birmingham. Enquirer: Australian Government

Morley, W. (2014). Common myths about your period. Retrieved 262019 from: http://www.womenshealth.answers.com/menstruation/common-myths-about-your-period

Nayak, S., (2016). A study on practices regarding menstrual hygiene among adolescent girls of urban areas of Jabalpur District. International Journal of Medical Sciences \& Public Health, 5, 2355-2357. https://doi.org/10.5455/ijmsph.2016.23042016483

Oche, M. O., Umar, A. S., Gana, G. J., \& Ango, J. T. (2012). Menstrual health: the unmet needs of adolescent girls' in Sokoto, Nigeria. Scientific Research and Essays, 7(3), 410-418. https://doi.org/10.5897/SRE11.1842

Pandey, A. (2014). Challenges experienced by adolescent girls while menstruation in Kathmandu, Valley: A qualitative study. Journal of Community Medicine \& Health Education, 4(285), 2161-0711. https://doi.org/10.4172/2161-0711.1000285

Parajuli, P., Paudel, N., \& Shrestha, S. (2017). Knowledge and practices regarding menstrual hygiene among adolescent girls of rural Nepal. Journal of Kathmandu Medical College, 5(1), 23-27. https://doi.org/10.3126/jkmc.v5i1.18262

Phani Madhavi, K.V. et al. (2019). Menstrual hygiene and practices among adolescent girls in rural Visakhapatnam: 
a cross-sectional study. Int $J$ Community Med Public Health, 6(1), 432-436. DOI: http://dx.doi.org/10.18203/2394-6040.ijcmph20185284

Poureslami, M., \& Osati-Ashtiani, F. (2002). Assessing knowledge, attitudes, and behavior of adolescent girls in suburban districts of Tehran about dysmenorrhea and menstrual hygiene. Journal of International Women's Studies, 3(2), 51-61.

Quazi, S.Z., Gaidhane, A., \& Singh, D. (2009). Beliefs and practices regarding menstruation among the adolescent girls of high schools and junior colleges of the rural areas of Thane district. J DMIMSU, 2, 76-71.

Kaur, R., Kaur, K., \& Kaur, R. (2018). Menstrual hygiene, management, and waste disposal: Practices and challenges faced by girls/women of developing countries. Journal of environmental and public health, 2018. https://doi.org/10.1155/2018/1730964

Rao, S., Joshi, S., \& Kanade, A. (2009). Height velocity, body fat and menarcheal age of Indian girls. Indian Pediatr, 35, 619-628.

Sharma, P., Malhotra, C., Taneja, D. K. et al. (2008). Problems related to menstruation amongst adolescent girls Indian Journal of Paediatricians, 75, 125-129. https://doi.org/10.1007/s12098-008-0018-5

Setia, M. S. (2016). Methodology series module 1: Cohort studies. Indian J Dermatol. 61, 21-5. https://doi.org/10.4103/0019-5154.174011

Thakre, S. B., Thakre, S. S., Reddy, M., Rathi, N., Pathak, K., \& Ughade S. (2011). Menstrual hygiene: Knowledge and practice among adolescent school girls of Saoner, Nagpur district. Journal of Clinical and Diagnostic Research, 5 (5), 1027-1033. Retrieved from www.jcdr.net

UNESCO. (2014). Puberty education and menstrual hygiene management. Paris, UNESCO.

UNICEF. (2008). Bangladesh: Tackling menstrual hygiene taboos. Sanitation and Hygiene Case Study No. 10. Retrieved April 1 2019,from http://www.unicef.org/wash/files/10_case_study_BANGLADESH_4web.pdf

Wateraid.org. Module one: Menstrual Hygiene Basics. (2012). Retrieved March 25 2019, from http://www.wateraid.org/ /media/Files/Global/MHM\%20files/Module1_HR.pdf_

\section{Copyrights}

Copyright for this article is retained by the author(s), with first publication rights granted to the journal.

This is an open-access article distributed under the terms and conditions of the Creative Commons Attribution license (http://creativecommons.org/licenses/by/4.0/). 